\title{
TITLE:
}

\section{Flash chemistry: flow chemistry that cannot be done in batch.}

$\operatorname{AUTHOR}(S)$ :

Yoshida, Jun-ichi; Takahashi, Yusuke; Nagaki, Aiichiro

\section{CITATION:}

Yoshida, Jun-ichi ...[et al]. Flash chemistry: flow chemistry that cannot be done in batch.. Chemical communications 2013, 49(85): 9896-9904

\section{ISSUE DATE:}

2013-11-04

\section{URL:}

http://hdl.handle.net/2433/192988

\section{RIGHT:}

(C) The Royal Society of Chemistry 2013; This is not the published version. Please cite only the published version.; この論文は出版社版で ありません。引用の際には出版社版をご確認ご利用ください。 


\title{
Flash chemistry: Flow chemistry that cannot be done in batch $\uparrow$
}

\author{
Jun-ichi Yoshida,* Yusuke Takahashi, and Aiichiro Nagaki \\ Received (in $X X X, X X X)$ Xth $X X X X X X X X X 20 X X$, Accepted Xth $X X X X X X X X X 20 X X$ \\ DOI: 10.1039/b000000x
}

\begin{abstract}
5 Flash chemistry based on high-resolution reaction time control using flow microreactors enables chemical reactions that cannot be done in batch and serves as powerful tools for laboratory synthesis of organic compounds and production in chemical and pharmaceutical industries.
\end{abstract}

10

From new materials to new medicinal agents, the central role of organic synthesis is expanding nowadays. Driven by remarkable improvements in our understanding of factors governing organic reactions and by increasingly powerful 15 instrumentation and analytical tools, the influence of organic synthesis has been extended to virtually all areas of science. ${ }^{1}$

We usually run reactions in batch reactors such as flasks for synthesis in chemistry laboratories. This is presumably because batch reactors are easy to handle for us. Another advantage of 20 batch reactors is that it is easy for us to imagine how a reaction proceeds in them. When we add a reagent or a catalyst to a solution of a starting material in a flask, a reaction starts. In some cases, we heat a mixture to initiate a reaction. Most of the reactions that we are using for organic synthesis were developed 25 in flasks, and it is not too much to say that organic chemists have been studying flask chemistry. Flask chemistry is chemistry under the constraint of the flask.

It should be noted, however, that there are other type of reactors, continuous flow reactors. ${ }^{2,3,4}$ Recently, it became 30 possible to conduct chemical reactions in a flow reactor in laboratory synthesis. Although large-scale productions of heavy chemicals in the industry have been carried out in continuous flow systems, the use of flow reactors in the production of fine chemical and pharmaceutical industry has just started recently.

35 Continuous flow synthesis is usually carried out using channel- or tube-type reactors. Starting materials and reagents are fed at the inlets of the reactor by pumping. There are several advantages of continuous flow synthesis in comparison with batch synthesis. For example, continuous flow processes are 40 generally more suitable for automation than batch processes. Because solutions of a starting material and a reagent are fed by pumps, on/off of the flow and the flow rate can be easily changed and programmed by a computer. Switching of bulbs enables reactions of various combinations of substrates and reagents in a 45 sequential way. ${ }^{5}$ Flow synthesis enables the use of hazardous chemicals safely. ${ }^{6}$ Dangerous reactions can be done in a controlled way under continuous flow mode. However, there is another important feature of flow chemistry. Flow chemistry enables reactions that cannot be done in batch, opening a new 50 possibility of chemical synthesis. In this feature article we focus on the development of such a field of flow chemistry, which is called flash chemistry. ${ }^{7}$ Flash chemistry offers integrated scheme for extremely fast reactions involving highly reactive unstable species on a preparative scale on time scales of a second or less, 55 which cannot be achieved by batch chemistry.

\section{High-resolution reaction time control}

In a flow reactor, the reaction proceeds as a reactant travels through the reactor. Therefore, the concentration of a reactant ${ }_{60}$ decreases with an increase in the distance from the inlet of the reactor (Figure 1). The concentration of a product increases and reaches a maximum at the outlet of the reactor if overreaction or decomposition of the product does not occur. It is also important to note that the concentrations of a reactant and a product do not ${ }_{65}$ change with the progress of operation time in a steady state. Therefore, the reaction time in a flow reactor can correlate to the space position inside of the reactor. This means that the reaction time can be controlled by adjusting the length of a flow reactor, although the reaction time also changes with the flow speed. 70

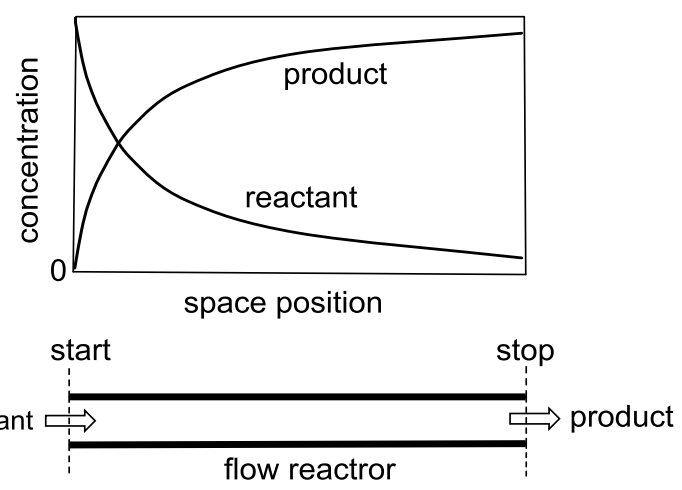

Figure 1. Reaction profile in a flow reactor

75 The length of time that the solution remains in the reactor is called the residence time. Therefore, the reaction time can be controlled by the residence time. One of the most advantageous features of flow reactors is precise residence time control by adjusting the length of the channel or tube and the flow speed. ${ }_{80}$ This leads to precise reaction time control.

The residence time or reaction time can be greatly reduced by shortening the length of the channel or tube. By increasing the flow speed, the residence time can also be reduced. For example, the mean residence time in a flow reactor of the length of $10 \mathrm{~mm}$ 85 at the flow speed of $1 \mathrm{~m} / \mathrm{s}$ is calculated to be $10 \mathrm{~ms}$ (Figure 2). Although there exists the distribution of the residence time, hereafter we consider only the mean residence time for simplicity of the discussion. If we want to reduce the reaction time to $5 \mathrm{~ms}$, 
we just simply need to reduce the length of the reactor to $5 \mathrm{~mm}$.

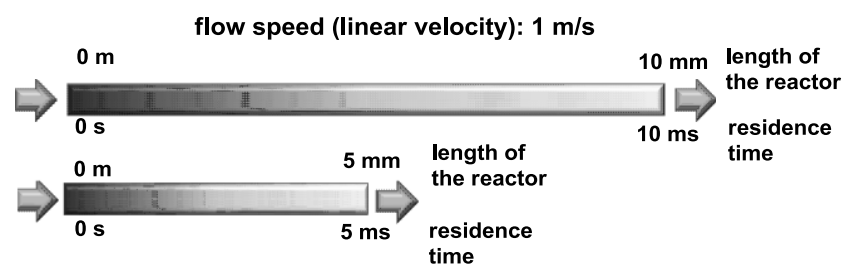

5 Figure 2. Relationship between the length of a flow reactor and the residence time.

Reactions are often started by mixing two reaction components and are stopped by adding a quenching reagent. Therefore, the 10 reaction time is defined as the time between the first mixing and the mixing with a quenching reagent. In a flow reactor, the reaction time is defined as the residence time between a reagent inlet and the position of the quencher inlet, and can be precisely controlled by adjusting the length between these positions (Figure $153)$.

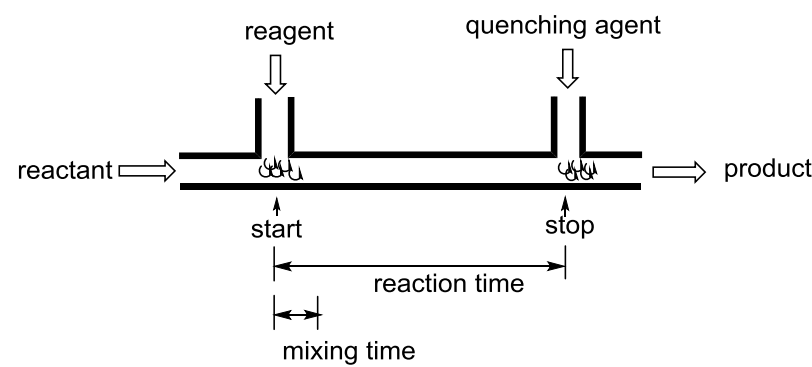

Figure 3. Control of reaction time by adjusting the residence time 20 between the introduction of a reagent and a quenching reagent with fast mixing.

Can we control the reaction time by adjusting the length of a macro flow reactor and flow speed? Yes, the above discussion 25 can be applied not only to flow microreactors but also to flow macroreactors, if the reaction time is relatively long. However, micro is essential for the control of reaction time of extremely fast reactions. Why is micro necessary? The residence time can be greatly reduced to millisecond order by reducing the length of 30 a microchannel or a microtube in a flow microreactor system. However, the lengths of reactors are usually not on micrometer order, but on centimeter order. The micro is necessary for mixing. If we wish to adjust the reaction time to $1 \mathrm{~s}$, the time for mixing a substrate and a reagent should be much less than $1 \mathrm{~s}$. The same is 35 true for the quenching. Such fast mixing is only possible using micro structures. Mixing occurs because of molecular diffusion. The time needed for molecular diffusion is proportional to the square of the length of the diffusion path. The marked shortening of the diffusion path in micromixers results in a mixing speed 40 unobtainable in a macroreactor. Therefore, micro is essential for the control of reaction time, which ranges from milliseconds to second time scale.

How does mixing take place in batch reactors by stirring? Mixing in a solution phase is defined as a phenomenon that 45 creates homogeneity of all species in the solution. One might think that such homogeneity is achieved immediately after two solutions are combined with vigorous stirring, but this is not true. It takes time (usually 0.01 - several seconds) to achieve homogeneity even with maximum turbulence produced by 50 vigorous stirring. ${ }^{8}$
To get better mixing we have to use micromixers. ${ }^{9,10}$ In micromixers, the solutions to be mixed are distributed into several segments of flows of small width using the microstructure of the device. Mixing takes place in the resulting stream through 55 the interfaces of the segments of flows by virtue of the short diffusion path, and a homogeneous solution is produced in a short period (Figure 4). According to the theory of molecular diffusion, mixing times can be reduced to millisecond order if the width of flows are reduced to micrometer order. This is indeed the case.

${ }_{60}$ Although T-shaped micromixers are very simple in structure and are easy to fabricate by conventional mechanical machining technology, they can be very effective in achieving fast mixing if the flow speed is high (Figure 4). At a low flow speed, mixing efficiency is rather low because of the laminar flow regime. ${ }_{65}$ However, when the flow speed exceeds a critical value, the intensity of mixing increases significantly. The engulfment flow regime caused by stream energy ${ }^{11}$ seems to be responsible for fast mixing. The threshold velocity depends on the size and shape of the microchannels. The reduced possibility of clogging ${ }^{12}$ is also 70 an advantage of simple T-shaped micromixers, because the channel size is large compared with multilaminationtype micromixers. T-shaped micromixers with $250-500 \mu \mathrm{m}$ inner diameter are popular.

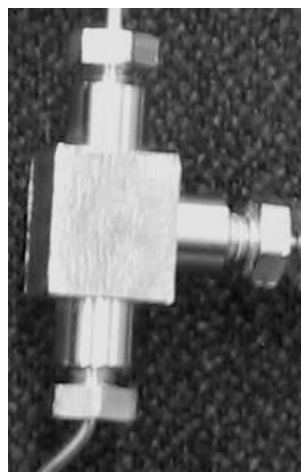

Figure 4. T-shaped micromixer

Thus, flow systems consisting of micromixers and microreactors are quite effective for precise control of reaction 80 times on the time scales of a second or less. The feature of short and precise reaction time control is extremely useful in controlling reactions involving unstable short-lived reactive intermediates. This feature is also useful for conducting reactions giving products that are unstable under the reaction conditions. 85

Control of fast consecutive reactions involving unstable intermediates

We often encounter a problem of control of consecutive 90 reactions. Let us consider a simple consecutive reaction shown in Scheme $1 . \mathbf{S}$ is a substrate (reactant), $\mathbf{I}$ is an unstable intermediate, and $\mathbf{B}$ is an undesired by-product produced by decomposition of $\mathbf{I}$. Intermediate $\mathbf{I}$ is transformed to a desired product $\mathbf{P}$ by adding a quenching agent before decomposition of $\mathbf{I}$. For simplicity, we 95 assume a sequence of first-order processes (rate constants: $k_{l}$ and $k_{2}$ ). We also assume that the quenching reaction of $\mathbf{I}$ to obtain $\mathbf{P}$ is much faster than its decomposition to give $\mathbf{B}$. 


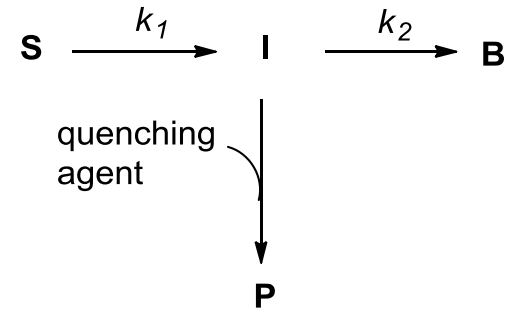

Scheme 1. A general scheme of consecutive reactions

When $k_{2}$ is much smaller than $k_{l}$, we can see that the reaction ${ }_{5} \mathbf{S} \rightarrow \mathbf{I}$ takes place first and goes nearly to completion before the reaction of $\mathbf{I} \rightarrow \mathbf{B}$ occurs. After completion of the reaction $\mathbf{S} \rightarrow \mathbf{I}$, the addition of a quenching agent leads to the production of desired product $\mathbf{P}$ in good yield. We can add a quenching agent over a wide range of reaction times to get a good yield of $\mathbf{P}$. The 10 increase in the reaction rates $k_{2}$ changes the situation even if $k_{2}$ is smaller than $k_{l}$. The reaction $\mathbf{S} \rightarrow \mathbf{I}$ takes place first, but before its completion the reaction $\mathbf{I} \rightarrow \mathbf{B}$ occurs. $\mathbf{I}$ is accumulated in acceptable yields only over a limited time range.

Let us consider the case where $k_{l}=10 \mathrm{~h}^{-1}$ and $k_{2} / k_{l}=0.01$. As 15 shown in Figure 5, $\mathbf{S}$ is consumed within $0.5 \mathrm{~h}$. The concentration of $\mathbf{P}$ increases with an increase in reaction time and then decreases gradually because of the formation of $\mathbf{B}$. The reaction time should be longer than ca. $0.25 \mathrm{~h}$ and should be shorter than ca. $0.6 \mathrm{~h}$ to get a yield higher than $90 \%$. This is easy to do with 20 batch reactors such as flasks. We need to add a quenching agent ca. $0.5 \mathrm{~h}$ after we started the reaction.

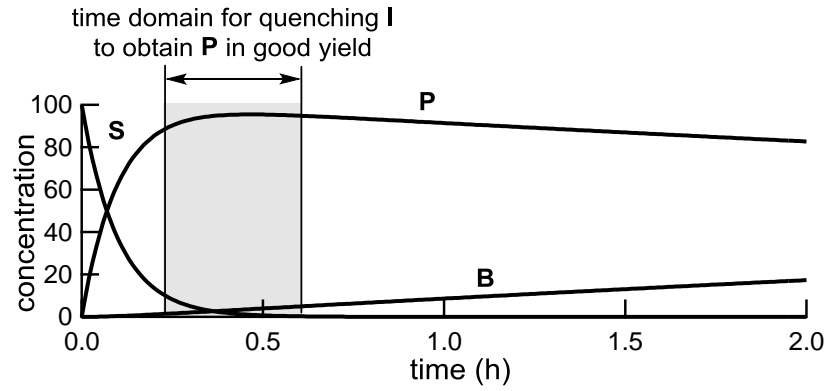

Figure 5. A variation of the concentrations of reaction 25 components against time $\left(k_{l}=10 \mathrm{~h}^{-1}\right.$ and $\left.k_{2} / k_{l}=0.01\right)$.

When the reaction is much faster, the reaction cannot be done in a controlled way in batch. For example, when $k_{l}=10 \mathrm{~s}^{-1}$ and $k_{2} / k_{1}=0.01$, the reaction time should be longer than ca. $0.25 \mathrm{~s}$ 30 and should be shorter than ca. $0.6 \mathrm{~s}$ to get a yield higher than $90 \%$ as shown in Figure 6. This means a quenching agent should be added precisely in this time domain. Otherwise we cannot get the desired product $\mathbf{P}$ in good yield. It should be noted that this kind of high-resolution reaction-time control cannot be achieved in 35 flask chemistry. For this purpose the use of a flow microreactor system equipped with micromixers is essential.

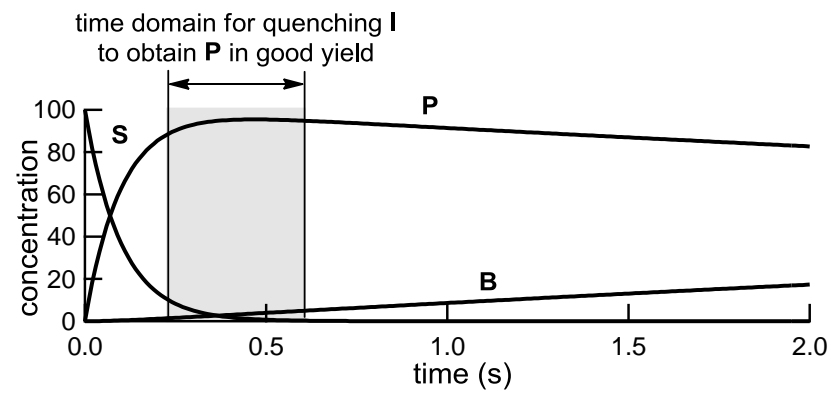

Figure 6. A variation of the concentrations of reaction 40 components against time $\left(k_{l}=10 \mathrm{~s}^{-1}\right.$ and $\left.k_{2} / k_{l}=0.01\right)$.

\section{Temperature-residence time map}

In the previous section, we discussed the importance of the residence time control in reactions involving unstable 45 intermediates. The following study on the deprotonation of styrene oxide with $s$-BuLi followed by trapping of the resulting $\alpha$-phenyloxiranyllithium (1) with iodomethane demonstrates the power of our approach based on the concept of flash chemistry (Figure 7$)^{13}$. Although 1 could be generated from styrene oxide 50 using $t$-BuLi or $s$-BuLi in the presence of TMEDA at $-98{ }^{\circ} \mathrm{C}$ in a conventional batch reactor, ${ }^{14}$ the use of $s$-BuLi in the absence of TMEDA caused decomposition even at $-98{ }^{\circ} \mathrm{C}$. A flow microreactor enables us to conduct the transformation at higher temperatures such as ca. $-70^{\circ} \mathrm{C}$. 55

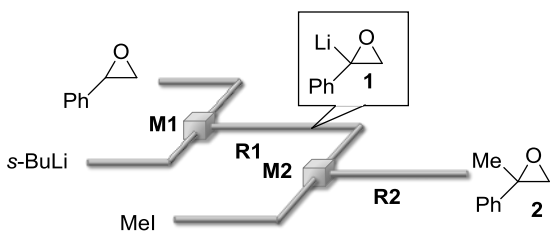

Figure 7. Deprotonation of styrene oxide with $s$-BuLi followed by the reaction with iodomethane in a flow microreactor system.

60

The reaction profile at $-68{ }^{\circ} \mathrm{C}$ is shown in Figure 8. By choosing an appropriate residence time for quenching (addition of iodomethane), methylated product $\mathbf{2}$ was obtained in a high yield.

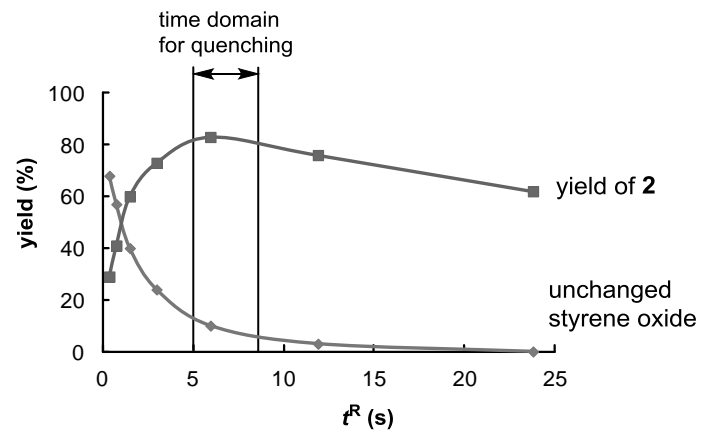

Figure 8. Plots of the amount of unchanged styrene oxide and the yield of the methylated product against the residence time $\left(t^{\mathrm{R}}\right)$ at $-68^{\circ} \mathrm{C}$.

70

Because the rates of reactions generally depend on the temperature, temperature control is also important. Therefore, we invented a tool for analyzing reactions based on temperatureresidence time map. 
In Figure 9 the conversions of the styrene oxide are plotted against the temperature and the logarithm of the residence time. At low temperatures and short residence times, the conversion is low and the starting material remained unchanged. The 5 conversion increases with an increase in the temperature and the residence time, and the quantitative conversion is obtained at a high temperature-long residence time region.

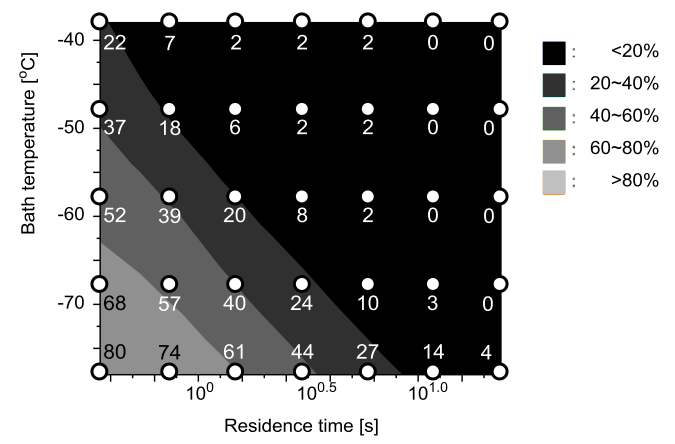

Figure 9. Contour plots with scatter overlay of the amount of 10 unchanged of styrene oxide against the temperature and the logarithm of the residence time.

In Figure 10 the yields of the methylated product $\mathbf{2}$ are plotted against the temperature and the logarithm of the residence time. 15 In a low temperature-short residence time region, the yield is low because the starting material remained unchanged. The yield increases with an increase in the temperature and the residence time, but further increase in the temperature and the residence time causes a decrease in the yield because of decomposition of ${ }_{20} \alpha$-phenyloxiranyllithium (1).

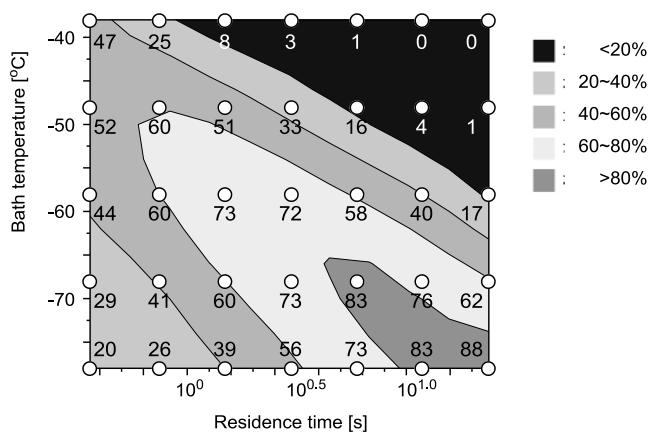

Figure 10. Contour plots with scatter overlay of the yield of the methylated product $\mathbf{2}$ against the temperature and the logarithm of the residence time.

25

It is important to note that the present temperature-residence time map is quite effective in revealing the stability and reactivity of highly reactive intermediates. Therefore, flow microreactor systems serve as powerful tools for mechanistic studies of 30 reactions invovling highly unstable intermediates. It is also noteworthy that the temperature-residence time maps serve as time efficient tools for optimizing reaction conditions. A map consisting of 30-40 data points can be made in a day or two by collecting product solutions under various conditions and 35 subsequent GC or LC analysis.

In the following part, we will highlight some applications of flash chemistry to demonstrate how powerful this concept is and how it can help to simplify the synthesis of useful organic compounds.

\section{A new approach to protecting-group-free synthesis}

Recently, the construction of complicated organic molecules without using protecting groups (protecting-group-free synthesis $)^{15}$ especially from the viewpoints of atom economy, ${ }^{16}$

${ }_{45}$ step economy, ${ }^{17}$ and redox economy ${ }^{18}$ has received significant research interest in the context of ideal synthesis ${ }^{19}$ and green sustainable chemistry. ${ }^{20}$ Generally, skeleton-building steps are the most difficult to avoid using protecting groups because such steps often use strongly basic nucleophilic reagents. Among such 50 reagents, organolithium reagents are the most reactive. Therefore, the present approach based on control of the residence time in a flow microreactor serves as a powerful method for protectinggroup-free synthesis using organolithium reagents, which is complementary to other approaches using less reactive and more 55 chemoselective reagents.

Organolithium species are most reactive organometallic species ${ }^{21}$ among those commonly used in organic synthesis, and the addition of organolithium species to a carbonyl group is one of the most fundamental reactions in organic chemistry. In fact, it 60 is well known that ketones react with organolithium species ${ }^{22}$ very rapidly, although ketones survive in the reactions of some less reactive organometallics. ${ }^{23}$ Therefore, organic chemistry textbooks say that a ketone carbonyl group should be protected prior to an organolithium reaction if it is not involved in the ${ }_{65}$ desired transformation. Otherwise, the organolithium species attacks the ketone carbonyl group. If organolithium chemistry could be free from such limitation, its power will be greatly enhanced. This is indeed the case. Organolithium reactions without protecting the ketone carbonyl groups can be 70 accomplished based on the concept of flash chemistry. Free ketone carbonyl groups can survive in organolithium reactions within a very short reaction time.

For example, aryllithium species bearing ketone carbonyl groups, which are generated by iodine-lithium exchange 75 reactions of the corresponding aryl iodides with mesityllithium, can be reacted with various electrophiles including aldehydes, chloroformates, and isocyanates using an integrated flow microreactor system (Figure 11). The residence time is a crucial factor and the transformation can be achieved only with a 80 residence time of $0.003 \mathrm{~s}$ or less. Long residence times lead to decomposition of the aryllithium species to give byproducts such as dimeric compounds.

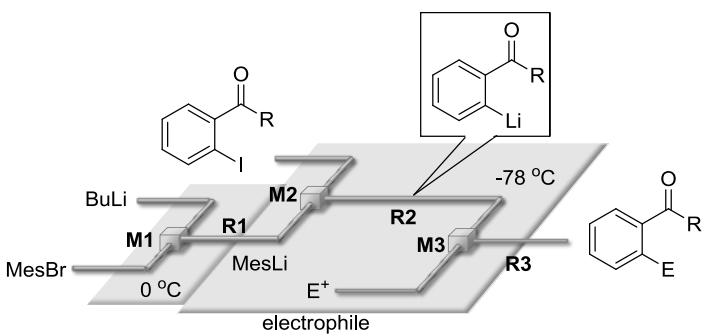

Figure 11. Generation and reactions of aryllithium species bearing ketone carbonyl groups

To demonstrate the potential of the flow microreactor method, 90 we synthesized Pauciflorol F (3), ${ }^{24,25}$ a natural product isolated from stem bark (Figure 12). The $\mathrm{I}-\mathrm{Li}$ exchange reaction of the 
iodoketone $\mathbf{4}$ to generate aryllithium bearing ketone $\mathbf{5}$ followed by reaction with 3,5-dimethoxybenzaldehyde was conducted using a flow microreactor system (the residence time in R2: 0.003 s) to give the desired product 6 in $81 \%$ isolated yield (1.06 $\mathrm{g}$ for 5 5 min operation). Presumably, dehydration took place upon the acidic work-up. Treatment with $\mathrm{HCl} / i$-PrOH in the presence of $\mathrm{O}_{2}$ in a batch reactor gave the cyclopentenone derivative 7 in $75 \%$ yield, which is known to be converted to Pauciflorol F (3).

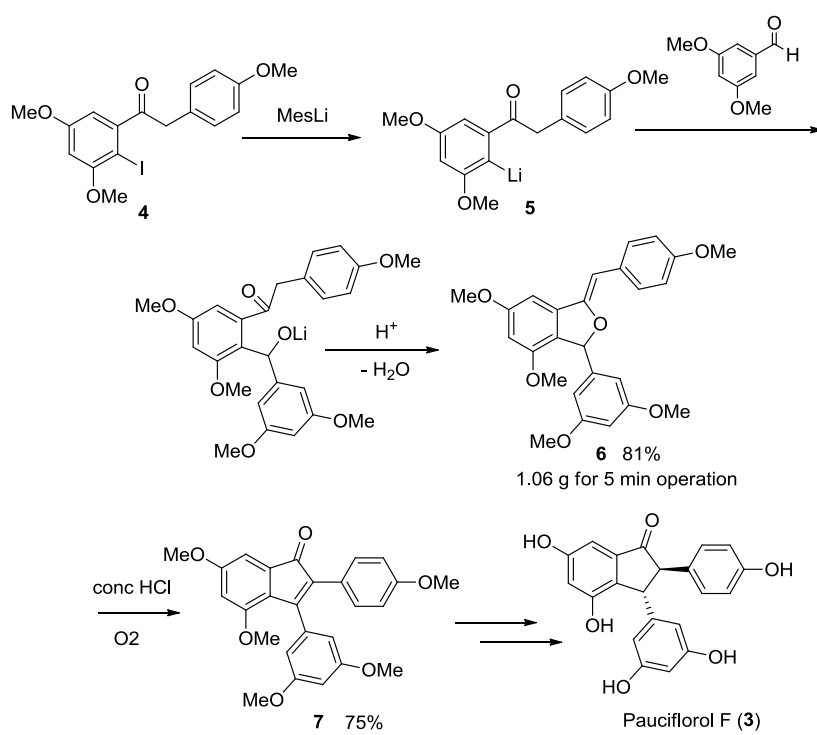

Figure 12. Synthesis of Pauciflorol F (3) using a flow microreactor system.

Various organolitium species including aryllthium species 15 bearing electrophilic functional groups such as ketone and ester carbonyl groups, ${ }^{26}$ nitro group, ${ }^{27}$ and cyano group ${ }^{28}$ can be successfully generated and be reacted with various electrophiles in flow microreactor systems (Figure 13). $o$-Bromophenyllthium spcies, which rapidly undergo $\beta$-elimination to give benzyne, can 20 also be generated and used for reactions with electrophile by adjusting the residence time. ${ }^{29}$ Perfluoroalkyllthium species, which are known to easily undergo $\alpha$ - or $\beta$-elimination can also be generated and used for reactions with electrophiles using flow microreactor sytems. ${ }^{30}$ Similary 1,2-dichlorovinyllithium can be 25 immediately reacted with electrophiles, although it undergoes $\beta$ elimination with a longer residence time at higher temperatures. ${ }^{31}$

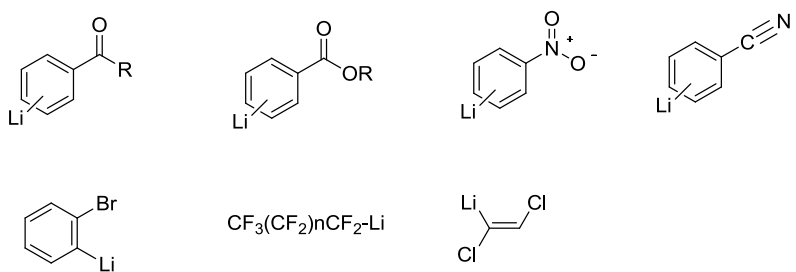

${ }_{30}$ Figure 13. Unstable organolithium species

\section{Multi-step synthesis}

The concept of flash chemistry is applicable to multi-step synthesis. Sequential introduction of three electrophiles into 35 1,3,5-tribromobenzene based on $\mathrm{Br} / \mathrm{Li}$ exchange reaction was achieved using an integrated flow microreactor system ${ }^{32}$ consisting of six micromixers and six microtube reactors as shown in Figure 14. ${ }^{33}$ This method enables flash synthesis of methyl ester $(\mathbf{8})$ of TAC-101 $(\mathbf{9})^{34}$, which is a synthetic retinoid 40 with selective binding affinity for RAR- $\alpha$ and its analogues in good yields. The total residence time from 1,3,5-tribromobenzene to compound $\mathbf{8}$ was ca. $13 \mathrm{~s}$, and the productivity of $\mathbf{8}$ was 100 $200 \mathrm{mg} / \mathrm{min}$.

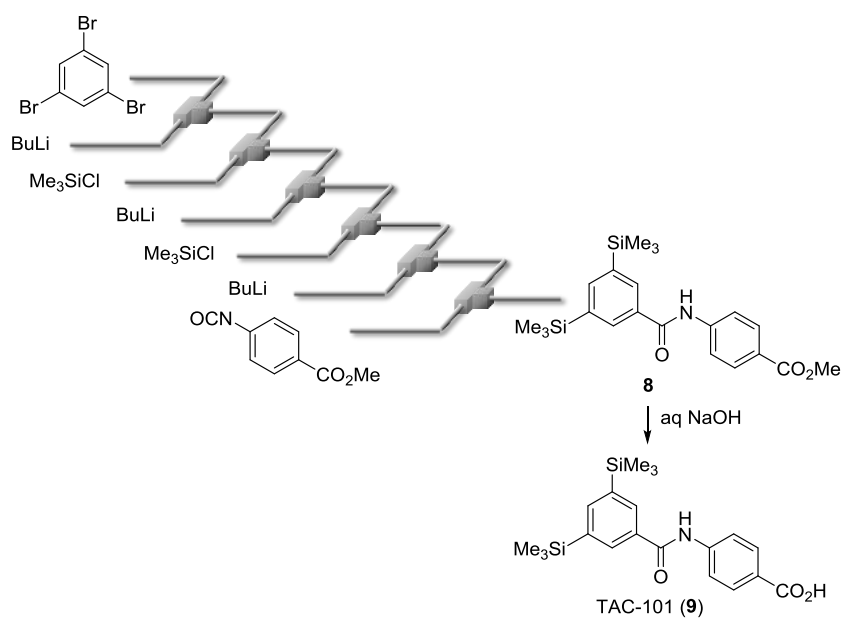

Figure 14. Synthesis of TAC-101 (7) using an integrated flow microreactor sytem.

\section{${ }_{50}$ A new approach to asymmetric synthesis}

Chiral organometallics ${ }^{35}$ provide powerful intermediates for the synthesis of enantioenriched compounds. In general, configurationally stable organometallics are used for highly enantioselective transformations, because the use of 55 configurationally unstable organometallics ${ }^{36}$ usually leads to rapid epimerization before they can react with electrophiles, even if such intermediates are produced enantioselectively. Flow microreactor systems enable the rapid generation of configurationally unstable organometallics, and allow their 60 reaction with electrophiles before they epimerize based on highresolution control of the residence time.

The addition of organolithium species to conjugated enyne $\mathbf{1 0}$ bearing a carbamoyl group as a directing group in the presence of a chiral ligand such as sparteine to generate chiral 65 organolithium intermediate $\mathbf{1 1},{ }^{37}$ and the subsequent reaction with electrophiles using an integrated flow microreactor system was studied (Figure 15). ${ }^{38}$ Organolithium intermediate 11 quickly undergoes epimerization and the success of enantioselective synthesis relies on the control of the residence time in 70 microreactor $\mathbf{R} 2\left(t^{\mathrm{R} 2}\right)$ to avoid the epimerization.

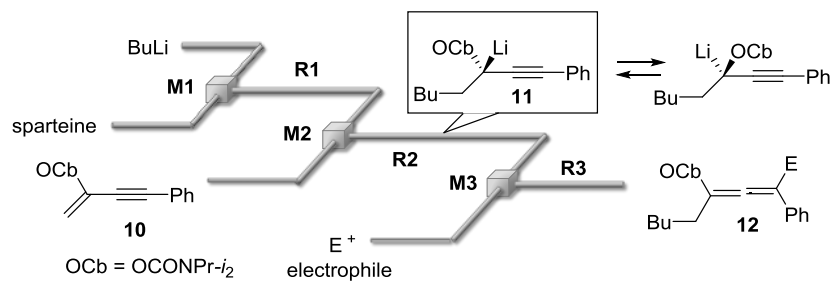

Figure 15. Asymmetric carbolithiation of a conjugated enyene.

As profiled in Figure 16 the yield of the product $\mathbf{1 2}$ obtained by using methanol as an electrophile $\left(\mathrm{E}^{+}=\mathrm{H}^{+}\right)$increased with increasing $t^{\mathrm{R}}$ and temperature. In contrast, the enantiomeric composition (ec) decreased with increasing $t^{\mathrm{R} 2}$ and temperature, 80 presumably because of epimerization of the intermediate 11 . This 
result means that the decrease of enantiomeric composition resulted from epimerization of the lithiated species rather than its formation step. The residence time-temperature domain that gave both a high yield $(>90 \%)$ and a high ec $(>90 \%)$ was very small.

5 However, it is noteworthy that when we carried out the reaction in this domain (e.g., residence time: $25 \mathrm{~s}$, Temperature: $-78{ }^{\circ} \mathrm{C}$ ), the desired product, the enantioenriched allene 12 was obtained in a high yield $(91 \%)$ with a high selectivity $(91 \%$ ec). In contrast, the reaction using a batch macro reactor (reaction time: $25 \mathrm{~s}$, 10 Temperature: $-78{ }^{\circ} \mathrm{C}$ ) gave the product in $99 \%$ yield with a low selectivity $(61 \%$ ec). Batch reactions under several conditions also led to low ec. Under the optimized conditions, various enantioenriched allenes were successfully synthesized in flow.

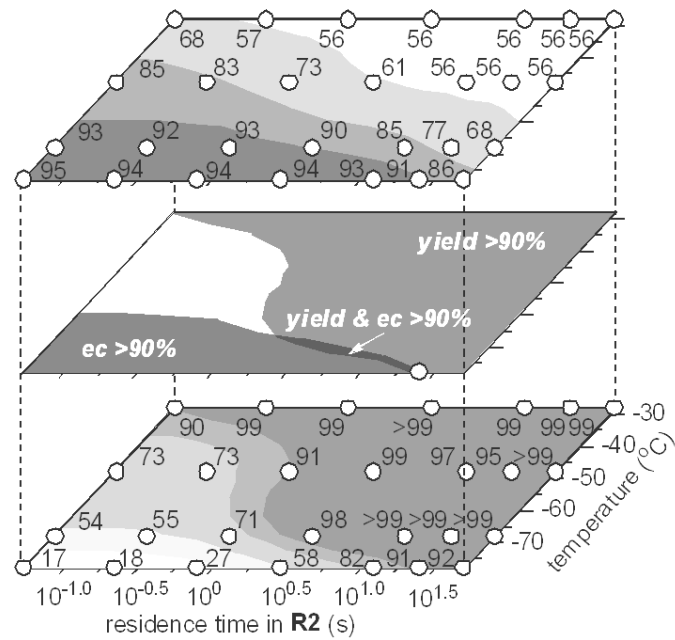

Figure 16. Temperature-residence time (in R2) map for the reaction of enyne in the presence of sparteine. A contour plot with scatter overaly of enantionmeric composition (ec) (upper) 20 and that of the yield (lower) of protonated product $\left(\mathrm{E}^{+}=\mathrm{H}^{+}\right)$, and the domain that gave both high ec $(>90 \%)$ and high yield $(>90 \%)$ (middle).

\section{A new approach to catalyst generation}

25 In the previous sections we discussed generation and reactions of highly unstable reactive species by taking advantage of highresolution residence time control using flow microreactors. This concept can be applied to generation of highly reactive shortlived catalyst before it decomposes. The following example 30 demonstrates that the concept has been successfully applied to the generation of an extremely efficient Pd catalyst for SuzukiMiyaura coupling. ${ }^{39,40,41}$

It is well known that generation of monoligated $[\mathrm{Pd}(0) \mathrm{L}]$ species $(\mathrm{L}=$ phosphine ligand) plays an important role in the ${ }_{35}$ Suzuki-Miyaura coupling reactions, because coordinatively unsaturated $[\mathrm{Pd}(0) \mathrm{L}]$ species are highly reactive towards oxidative addition of aryl halides $(\mathrm{ArX})$ to produce $[\mathrm{Pd}(\mathrm{Ar}) \mathrm{X}(\mathrm{L})]$, a key intermediate in the coupling. ${ }^{42}$ However, $[\mathrm{Pd}(0) \mathrm{L}]$ is highly unstable and its generation at high concentrations is very difficult.

40 The flash method involving 1:1 mixing of $\mathrm{Pd}(\mathrm{II})$ and $\mathrm{L}$ in flow microreactor enables the generation of unstable monoligated $[\mathrm{Pd}(\mathrm{II}) \mathrm{L}]$ species as a precursor at high concentrations in the absence of coupling substrates. In the next step, [Pd(II)L] species is transferred, before it decomposes, to a reaction vessel for 45 coupling reactions, where it may be reduced to give highly reactive $[\mathrm{Pd}(0) \mathrm{L}]$.
For example, a solution of $\mathrm{Pd}(\mathrm{OAc})_{2}$ and that of $t-\mathrm{Bu}_{3} \mathrm{P}$ were introduced to a micromixer and the resulting solution was passed through a microtube reactor (the residence time: $0.65 \mathrm{~s}$ ). After a 50 steady state was reached, the resulting solution was dropped into a vessel containing a solution of $p$-bromotoluene, phenylboronic acid, and potassium hydroxide. After addition was complete, the mixture in the reaction vessel was stirred at room temperature, and the progress of the coupling reaction was monitored by GC 55 (Figure 17).

For comparison, three conventional methods were examined. In method $\mathrm{A}$, a solution of $t-\mathrm{Bu}_{3} \mathrm{P}$ in THF was added to a reaction vessel, and after $10 \mathrm{~s}$, a solution of $\mathrm{Pd}(\mathrm{OAc})_{2}$ in THF was added. In method $\mathrm{B}$, a solution of $\mathrm{Pd}(\mathrm{OAc})_{2}$ was added, and after $10 \mathrm{~s}$, a ${ }_{60}$ solution of $t-\mathrm{Bu}_{3} \mathrm{P}$ was added. In method $\mathrm{C}$, both solutions were added simultaneously to a reaction vessel (10 s). In all cases, 1 $\mathrm{mol} \%$ of $\mathrm{Pd}(\mathrm{OAc})_{2}$ and $1 \mathrm{~mol} \%$ of $t-\mathrm{Bu}_{3} \mathrm{P}$ based on $p$ bromotoluene were introduced to the reaction vessel. Notably, the catalytic activity strongly depends on the way of addition of ${ }_{65} \mathrm{Pd}(\mathrm{OAc})_{2}$ and $t$-Bu $\mathrm{Bu}_{3} \mathrm{P}$. As shown in Figure 17 , the reaction was complete within $5 \mathrm{~min}$ in the case of the flash method. However, in all conventional methods the reaction took much longer time to reach completion. The extremely high reactivity observed for the catalyst generated by the flash method seems to be attributed to 70 the quick generation of a highly unstable reactive catalyst precursor by fast micromixing of $\mathrm{Pd}(\mathrm{OAc})_{2}$ and $t-\mathrm{Bu}_{3} \mathrm{P}$ in the absence of coupling substrates and potassium hydroxide, and its transfer to the reaction vessel before it decomposes by virtue of the short residence time in the flow system.

75
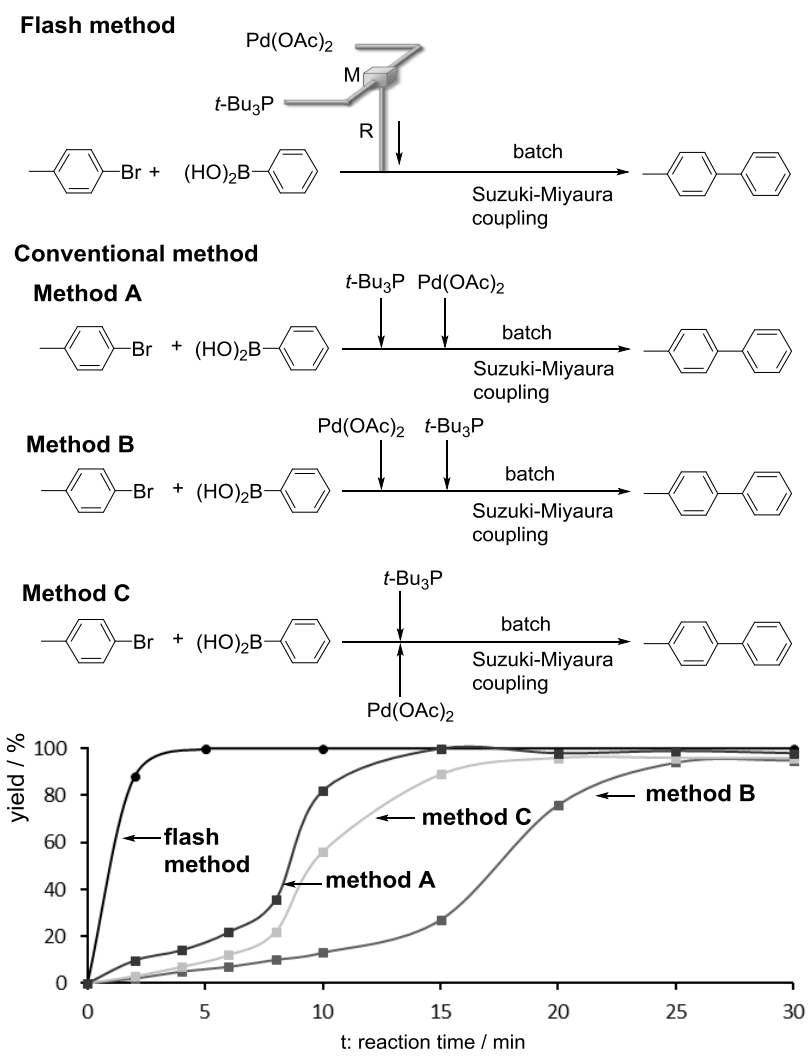

Figure 17. Suzuki-Miyaura coupling of $p$-bromotoluene and phenylboronic acid in the presence of $\mathrm{KOH}$ catalyzed by ${ }_{80}\left[\mathrm{Pd}(\mathrm{OAc})_{2}\right]-t-\mathrm{Bu}_{3} \mathrm{P}$. 
An in-line flow FT-IR spectroscopic analysis (ATR method) ${ }^{43}$ indicated the formation of $\left[\mathrm{Pd}(\mathrm{OAc})_{2}-t-\mathrm{Bu}_{3} \mathrm{P}\right]_{2}(\mathbf{1 3})$ by fast $1: 1$ micromixing of $\mathrm{Pd}(\mathrm{OAc})_{2}$ and $t-\mathrm{Bu} 3 \mathrm{P}$ in the flow microreactor system, although an increase in the residence time caused its 5 decomposition to give the less active palladacycle 14 (Figure 18). The quick transfer of highly active $\mathbf{1 3}$ to the reaction vessel leads to extremely fast Suzuki-Miyaura coupling. The coupling reactions could be complete within $5 \mathrm{~min}$ even at room temperature. Aryl- or heteroarylboronic acids, which quickly 10 deboronate under basic conditions, could be also used as coupling partners, because the reactions can be conducted at lower temperatures and in a short time.

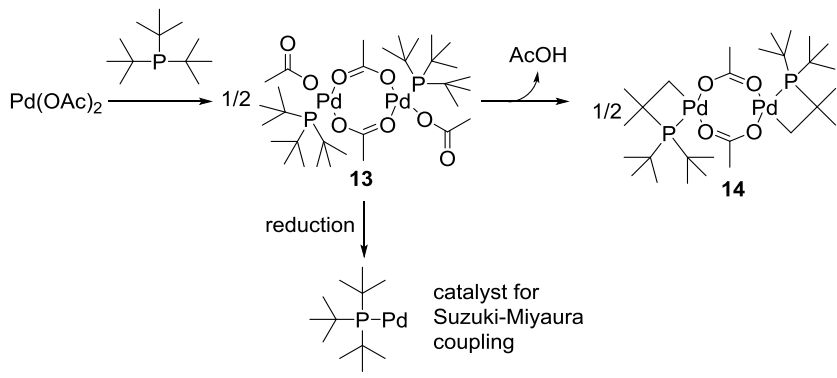

Figure 18. Generation of $\left[t-\mathrm{Bu}_{3} \mathrm{PPd}(0)\right]_{2}(\mathbf{1 3})$ from $\mathrm{Pd}(\mathrm{OAc})_{2}$ and $t$ - $\mathrm{Bu}_{3} \mathrm{P}$, and formation of palladacycle 14 .

\section{Industrial applications}

Flash chemistry using flow microreactor systems can be used for production on a relatively large scale. Although the reactor's capacity of a flow microreactor at any one time is small, the total production capacity over time is much greater than generally 25 believed, because the solution flows through the reaction chamber continuously. In fact, there are flow microreactors that fit in the palm of the hand that can produce thousand tones of product per year. Several attempts at industrial applications of flash chemistry have already been made to meet the demands of 30 the pharmaceutical and chemical industries. For example, Juliatype coupling of an organolithium compound with an aldehyde to produce an intermediate of anticancer drug, Halaven ${ }^{\mathrm{TM}}$ was examined using a flow microreactor system by Eisai. ${ }^{44}$ The test plant for the Grignard exchange reaction of 35 pentafluorobromobenzene with ethylmagnesium bromide was developed in the "highly efficient micro chemical process technology project" supported by NEDO, Japan. ${ }^{45}$

Flash chemistry using flow microreactor systems enables ondemand and on-site chemical production. This leads to less 40 energy consumption for storage and transportation of products. More notably, unstable chemical substances can be commercial products. Medical drugs of short life time can be synthesized in a hospital and are delivered to patients immediately. Agrochemicals that may be easy to decompose can be produced 45 very close to farms at an appropriate time and be distributed. Production at a place close to the final users of chemical substances also enables easy recycling of substances. Another important point for on-demand and on-site production is that such production is also benefitting from the viewpoint of residents 50 who live close to production sites, concerned about the chemicals. Such technology should lead to better understanding of the benefits and risks of chemicals.

\section{Conclusions}

55 The examples shown in this article and many other examples in the literature illustrate the potential of flash chemistry using flow microreactors in chemical science and chemical production. Flash chemistry serves as powerful method for protecting group free synthesis, multi-step synthesis, asymmetric synthesis, and ${ }_{60}$ generation of highly reactive catalysts. It is hoped that various types of applications of flash chemistry will be developed and widely utilized in laboratories and industries to meet future demands for highly efficient chemical synthesis and production.

65

\section{Acknowledgements}

This work was financially supported in part by the Grant-inAid for Scientific Research on Innovative Areas (No. 2015) from 70 the MEXT.

\section{Notes and references}

1 For example: (a) R. Noyori, Nat. Chem., 2009, 1, 5: (b) P. Kündig, Science, 2006, 314, 430

2 (a) T. Wirth, Microreactors in Organic Synthesis and Catalysis, Wiley75 VCH: Weinheim, 2008; (b) V. Hessel, A. Renken, J. C. Schouten and J. Yoshida, Micro Precess Engineering: Wiley-Blackwell, 2009; (c) P. Watts and C. Wiles, Micro Reaction Technology in Organic Synthesis, CRC Press: New York 2011.

3 Microreactor: (a) P. Watts and S. J. Haswell, Chem. Soc. Rev., 2005, 34,

80 235; (b) J. Yoshida, A. Nagaki, T. Iwasaki and S. Suga, Chem. Eng. Tech., 2005, 3, 259; (c) K. Geyer, J. D. C. Codee and P. H. Seeberger, Chem. Eur. J., 2006, 12, 8434; (d) G. Whitesides, Nature, 2006, 442 , 368; (e) A. J. deMello, Nature, 2006, 442, 394; (f) J. Kobayashi, Y. Mori and S. Kobayashi, Chem. Asian J., 2006, 1, 22; $(g)$ M. Brivio, W. 85 Verboom and D. N. Reinhoudt, Lab Chip, 2006, 6, 329; (h) B. P. Mason, K. E. Price, J. L. Steinbacher, A. R. Bogdan and D. T. McQuade, Chem. Rev., 2007, 107, 2300; (i) B. Ahmed-Omer, J. C. Brandtand and T. Wirth, Org. Biomol. Chem., 2007, 5, 733; (j) P. Watts and C. Wiles, Chem. Commun., 2007, 443; (k) T. Fukuyama, M. T. Rahman, M. Sato 90 and I. Ryu, Synlett, 2008, 151; (l) W. Lin, Y. Wang, S. Wang and H. Tseng, Nano Today, 2009, 4, 470; $(m)$ K. Geyer, T. Gustafsson and P. H. Seeberger, Synlett, 2009, 2382; (n) J .P. McMullen and K. F. Jensen, Annu. Rev. Anal. Chem., 2010, 3, 19; (o) S. Marrea and K. F. Jensen, Chem. Soc. Rev., 2010, 39, 1183; (p) D. Webb and T. F. Jamison,

95 Chem. Sci., 2010, 1, 675; $(q)$ J. Yoshida, H. Kim and A. Nagaki, ChemSusChem, 2011, 4, 331. (r) D. T. McQuade and P. H. Seeberger, J. Org. Chem., 2013, 78, 6384.

4 Recent examples: (a) A. Nagaki, K. Kawamura, S. Suga, T. Ando, M. Sawamoto and J. Yoshida, J. Am. Chem. Soc., 2004, 126, 14702; (b)

100 C.-C. Lee, et al., Science, 2005, 310, 1793; (c) L. Ducry and D. M. Roberge, Angew. Chem. Int. Ed., 2005, 44, 7972; (d) P. He, P. Watts, F. Marken and S. J. Haswell, Angew. Chem. Int. Ed., 2006, 45, 4146; (e) K. Tanaka, S. Motomatsu, K. Koyama, S. Tanaka and K. Fukase, Org. Lett., 2007, 9, 299; (f) H. R. Sahoo, J. G. Kralj and K. F. Jensen, Angew. 105 Chem. Int. Ed., 2007, 46, 5704; (g) C. H. Hornung, M. R. Mackley, I. R. Baxendale and S. V. Ley, Org. Process Res. Dev., 2007, 11, 399; $(h)$ T. Fukuyama, M. Kobayashi, M. T. Rahman, N. Kamata, and I. Ryu, Org. Lett., 2008, 10, 533; (i) T. Tricotet and D. F. O'Shea, Chem. Eur. J., 2010, 16, 6678; (j) D. L. Browne, M. Baumann, B. H. Harji, I. R. 110 Baxendale and S. V. Ley, Org. Lett., 2011, 13, 3312; (k) C. F. Carter, H. Lange, D. Sakai, I. R. Baxendale and S. V. Ley, Chem. Eur. J., 2011, 17, 3398; $(l)$ N. Zaborenko, M. W. Bedore, T. F. Jamison and K. F. Jensen, Org. Process Res. Dev., 2011, 15, 131; (m) A. C. Gutierrez and T. F. Jamison, Org. Lett., 2011, 13, 6414.

$115^{5}$ (a) S. Suga, M. Okajima, K. Fujiwara, and J. Yoshida, J. Am. Chem. Soc. 2001, 123, 7941; (b) S. Suga, M. Okajima, K. Fujiwara, and J. Yoshida, J. QSAR Comb. Sci. 2005, 24, 728.

6 J.C. Brandt, and T. Wirthl, Beilstein J. Org. Chem., 2009, 5, 30.

7 Flash chemistry is defined as a field of chemical synthesis where 120 extremely fast reactions are conducted in a highly controlled manner to produce the desired compounds with high selectivity. (a) J. Yoshida, Flash Chemistry. Fast Organic Synthesis in Microsystems: WileyBlackwell, 2008; (b) J. Yoshida, Chem. Commun., 2005, 4509; (c) J. Yoshida, A. Nagaki and T. Yamada, Chem. Eur. J., 2008, 14, 7450; (d) 
J. Yoshida, Chem. Record, 2010, 10, 332; (e) P. J. Nieuwland, K. Koch, N. van Harskamp, R. Wehrens, J. C. M. van Hest and F. P. J. T. Rutjes, Chem. Asian J., 2010, 5, 799 .

8 (a) P. Rys, Acc. Chem. Res., 1976, 10, 345; (b) P. Rys, Angew. Chem., Int. Ed., 1977, 16, 807.

9 Selected reviews on micromixing: (a) M. Kakuta, F. G. Bessoth, A. Manz, Chem. Rev., 2001, 101, 395; (b) V. Hessel, H. Löwe, F. Schönfeld, Chem. Eng. Sci., 2005, 60, 2479; Selected papers on micromixing: (c) T. J. Johnson, D. Ross, L. E. Locascio, Anal. Chem.,

2002, 74, 45; (d) G. H. Seong, R. M. Crooks, J. Am. Chem. Soc., 2002, 124, 13360; (e) H. Song, J. D. Tice, R. F. Ismagilov, Angew. Chem., 2003, 115, 792; Angew. Chem., Int. Ed., 2003, 42, 768; (f) B. Zheng, L. S. Roach, R. F. Ismagilov, J. Am. Chem. Soc., 2003, 125, 11170; $(g) \mathrm{H}$. Song, R. F. Ismagilov, J. Am. Chem. Soc., 2003, 125, 14613.

${ }^{15}{ }^{10}$ (a) S. Suga, A. Nagaki and J. Yoshida, Chem. Commun., 2003, 354; (b) A. Nagaki, M. Togai, S. Suga, N. Aoki, K. Mae and J. Yoshida, J. Am. Chem. Soc., 2005, 127, 11666.

11 A. Soleymani, H. Yousefi, I. Turunen, Chem. Eng. Sci. 2008, 63, 5291.

12 (a) S. L. Poe, M. A. Cummings, M. P. Haaf and D. T. McQuade,

20 Angew. Chem. Int. Ed. 2006, 45, 1544; (b) T. Horie, M. Sumino, T. Tanaka, Y. Matsushita, T. Ichimura and J. Yoshida, Org. Process Res. Dev. 2010, 14, 405; (c) D. L. Browne, B. J. Deadman, R. Ashe, I. R. Baxendale and S. V. Ley, Org. Process Res. Dev. 2011, 15, 693; (d) T. Noël, J. R. Naber, R. L. Hartman, J. P. McMullen, K. F. Jensen and S. 25 L. Buchwald, Chem. Sci., 2011, 2, 287.

${ }^{13}$ (a) A. Nagaki, E. Takizawa and J. Yoshida, J. Am. Chem. Soc., 2009, 131, 1654; (b) A. Nagaki, E. Takizawa and J. Yoshida, Chem. Lett., 2009, 38, 486; (c) A. Nagaki, E. Takizawa and J. Yoshida, Chem. Lett., 2009, 38, 1060; (d) A. Nagaki, E. Takizawa and J. Yoshida, Chem. Eur. $30 \quad$ J., 2010, 16, 14149.

14 (a) J. J. Eisch and E. J. Galle, J. Organomet. Chem., 1976, 121, C-10; (b) J. J. Eisch and E. J. Galle, J. Org. Chem., 1990, 55, 4835; (c) T. Satoh, Chem. Rev., 1996, 96, 3303; (d) V. Capriati, S. Florio, R. Luisi and A. Salomone, Org. Lett., 2002, 4, 2445; (e) V. Capriati, S. Florio 3 and R. Luisi, Chem. Rev., 2008, 108, 1918.

15 (a) I. S. Young and P. S. Baran, Nat. Chem., 2009, 1, 193; (b) R. W. Hoffmann, Synthesis, 2006, 3531.

${ }_{16}$ (a) B. M. Trost, Science, 1991, 254, 1471; (b) B. M. Trost, Angew. Chem. Int. Ed., 1995, 34, 259; (c) R. A. Sheldon, Pure Appl. Chem.,

40 2000, 72, 1233; (d) B. M. Trost, Acc. Chem. Res., 2002, 35, 695.

${ }^{17}$ P. A. Wender, V. A. Verma, T. J. Paxton and T. H. Pillow, Acc. Chem. Res,. 2008, 41, 40.

${ }^{18}$ N. Z. Burns, P. S. Baran and R. W. Hoffmann, Angew. Chem. Int. Ed., 2009, 48, 2854.

${ }_{45}{ }^{19}$ J. B. Hendrickson, J. Am. Chem. Soc., 1975, 97, 5784.

${ }^{20}$ M. Poliakoff, J. K. Fitzpatrick, T. R. Farren and P. T. Anastas, Science. 2002, 297, 807.

${ }^{21}$ (a) P. Knochel, Handbook of Functionalized Organometallics, WileyVCH, Weinheim, 2005; (b) W. E. Parham and C. K. Bradsher, Acc.

50 Chem. Res., 1982, 15, 300.

22 J. L. Rutherford, G. Ferry, J. M. Hawkins and O. Lyme, Preparation of novel substituted haloarene compounds US 7,273,938 B2, 2007.

${ }^{23}$ (a) X. Yang and P, Knochel, Chem. Commun., 2006, 2170; (b) X. Yang, T. Rotter, C. Piazza and P. Knochel, Org. Lett., 2003, 5, 1229; (c) F. F.

5 Kneisel and P. Knochel, Synlett, 2002, 1799.

${ }^{24}$ (a) S. A. Snyder, A. L. Zografox and Y. Lin, Angew. Chem., Int. Ed., 2007, 46, 8186; (b) S. A. Snyder, S. P. Breazzano, A. G. Ross, Y. Lin, and A. L. Zografos, J. Am. Chem. Soc., 2009, 131, 1753; (c) J. L. Jeffrey, and R. Sarpong, Org. Lett., 2009, 11, 5450.

${ }_{60}^{25}$ H. Kim, A. Nagaki and J. Yoshida, Nature Commun., 2011, 2, 264

${ }^{26}$ (a) A. Nagaki, H. Kim and J. Yoshida, Angew. Chem. Int. Ed., 2008, 47, 7833; (b) A. Nagaki, H. Kim, Y. Moriwaki, C. Matsuo and J. Yoshida, Chem. Eur. J., 2010, 16, 11167.

27 A. Nagaki, H. Kim and J. Yoshida, Angew. Chem. Int. Ed., 2009, 48, 658063.

${ }^{28}$ A. Nagaki, H. Kim, H. Usutani, C. Matsuo and J. Yoshida, Org. Biomol. Chem., 2010, 8, 1212

${ }^{29}$ (a) H. Usutani, Y. Tomida, A. Nagaki, H. Okamoto, T. Nokami and J. Yoshida, J. Am. Chem. Soc., 2007, 129, 3046; (b) A. Nagaki, Y.

- Tomida, H. Usutani, H. Kim, N. Takabayashi, T. Nokami, H. Okamoto and J. Yoshida, Chem. Asian. J., 2007, 2, 1513; (c) A. Nagaki, S. Yamada, M. Doi Y. Tomida, N. Takabayashi and J. Yoshida, Green Chem., 2011, 13, 1110; (d) A. Nagaki, D. Yamada, S. Yamada, M. Doi, Y. Tomida, N. Takabayashi and J. Yoshida, Aust. J. Chem., 2013, 66, 199.

${ }^{30}$ (a) T. Schwalbe, V. Autze, M. Hohmann and W. Stirner, Org. Process Res. Dev., 2004, 8, 440; (b) A. Nagaki, S. Tokuoka, S. Yamada, Y.
Tomida, K. Oshiro, H. Amii and J. Yoshida, Org. Biomol. Chem. 2011, 9. 7559.

${ }_{80}{ }^{31}$ (a) A. Nagaki, C. Matsuo, S. Kim, K. Saito, A. Miyazaki and J. Yoshida, Angew. Chem., Int. Ed., 2012, 51, 3245; (b) A. Nagaki, Y. Takahashi, S. Yamada, C. Matsuo, S. Haraki, Y. Moriwaki, S. Kim and J. Yoshida, J. Flow Chem., 2012, $2,70$.

32 (a) S. Suga, D. Yamada and J. Yoshida, Chem. Lett., 2010, 39, 404; (b)

85 J. Yoshida, K. Saito, T. Nokami and A. Nagaki, Synlett, 2011, 9, 1189.

${ }^{33}$ A. Nagaki, K. Imai and J. Yoshida, RSC Adv., 2011, 1, 758.

${ }^{34}$ (a) T. Yamakawa, H. Kagechika, E. Kawachi, Y. Hashimoto and K. Shudo, J. Med. Chem., 1990, 33, 1430; (b) N. A. Rizvi, J. L. Marshall, E. Ness, M. J. Hawkins, C. Kessler, H. Jacobs, W. D. Brenckman, Jr., J. 90 S. Lee, W. Petros, W. K. Hong and J. M. Kurie, J. Clin. Oncol., 2002, 20, 3522; (c) H. Kagechika and K. Shudo, J. Med. Chem., 2005, 48, 5875 .

${ }^{35}$ Chiral organometallics: (a) R. W. Hoffmann, Chem. Soc. Rev., 2003, 32 225; (b) J. A. Marshall, J. Org. Chem., 2007, 72, 8153; (c) C. M.

95 Crudden, B. W. Glasspoole and C. J. Lata, Chem. Commun., 2009, 6704. Chiral organolithiums: (d) J. Clayden, Organolithiums: Selectivity for Synthesis; Pergamon: Amsterdam, The Netherlands, 2002; Chapters 5 and 6; (e) D. M. Hodgson, Organolithiums in Enantioselective Synthesis; Springer: Berlin, Germany, 2003; $(f)$ D. 100 Hoppe and T. Hense, Angew. Chem., Int. Ed. Engl., 1997, 36, 2282; ( $g$ ) A. Basu, S. Thayumanavan, Angew. Chem., Int. Ed., 2002, 41, 716; $(h)$ P. Beak, D. R. Anderson, M. D. Curtis, J. M. Laumer, D. J. Pippel and G. A. Weisenburger, Acc. Chem. Res., 2000, 33, 715; (i) W. K. Lee, Y. S. Park and P. Beak, Acc. Chem. Res., 2009, 42, 224.

$105^{36}$ Enantioselective transformations could be sometimes achieved by dynamic kinetic resolution. P. Beak, A. Basu, D. J. Gallagher, Y. S. Park and S. Thayumanavan, Acc. Chem. Res., 1996, 29, 552.

${ }^{37}$ R. B. Chedid, M. Brümmer, B. Wibbeling, R. Fröhlich and D. Hoppe, Angew. Chem., Int. Ed., 2007, 46, 3131 .

$11{ }^{38}$ Y. Tomida, A. Nagaki and J. Yoshida, J. Am. Chem. Soc., 2011, 133, 3744

${ }^{39}$ For reviews, see: (a) A. Suzuki, Acc. Chem. Res., 1982, 15, 178; (b) N. Miyaura and A. Suzuki, Chem. Rev., 1995, 95, 2457; (c) S. Kotha, K. Lahiri and D. Kashinath, Tetrahedron, 2002, 58, 9633; (d) N. Miyaura, Bull. Chem. Soc. Jpn., 2008, 81, 1535.

${ }^{40}$ A. Nagaki, N. Takabayashi, Y. Moriwaki and J. Yoshida, Chem. Eur. J. $2012, \mathbf{1 8}, 11871$.

${ }^{41}$ For examples of catalytic cross-coupling reaction using microreactors: (a) G. M. S. Greenway, J. Haswell, D. O. Morgan, V. Skelton and P. String, Sens. Actuators. B., 2000, 63, 153; (b) T. Fukuyama, M. Shinmen, S. Nishitani, M. Sato and I. Ryu, Org. Lett., 2002, 4, 1691; (c) E. Comer and M. G. Organ, J. Am. Chem. Soc., 2005, 127, 8160; (d) Y. Uozumi, Y. M. A. Yamada, T. Beppu, N. Fukuyama, M. Ueno and T. Kitamori, J. Am. Chem. Soc., 2006, 128, 15994; (e) E. R. Murphy, J. 125 R. Martinelli, N. Zaborenko, S. L. Buchwald and K. F. Jensen, Angew. Chem. Int. Ed., 2007, 46, 1734; (f) J. Jin, M. Cai and J. Li, Synlett, 2009 15, 2534; $(g)$ B. Ahmed-Omer, D. A. Barrow and T. Wirth, Tetrahedron Lett., 2009, 50, 3352; (h) A. Nagaki, A. Kenmoku, Y. Moriwaki, A. Hayashi and J. Yoshida, Angew. Chem., Int. Ed., 2010, 130 49, 7543; (i) Z. Y. Xiao, Y. Zhao, A. Wang, J. Perumal and D. Kim, Lab Chip, 2011, 11, 57; (j) T. Noël and S. L. Buchwald, Chem. Soc. Rev., 2011, 40, 5010; (k) W. Shu and S. L. Buchwald, Angew. Chem., Int. Ed., 2012, 51, 5355; (l) A. Nagaki, Y. Moriwaki, S. Haraki, A. Kenmoku, A. Hayashi and J. Yoshida, Chem. Asian J., 2012, 7, 1061; 135 (m) A. Nagaki, Y. Moriwaki and J. Yoshida, Chem. Commun., 2012, 48, 11211.

${ }^{42}$ (a) A. F. Littke, G. C. Fu, Angew. Chem., 1998, 110, 3586; Angew. Chem. Int. Ed., 1998, 37, 3387; (b) A. F. Littke, C. Dai, G. C. Fu, J. Am Chem. Soc., 2000, 122, 4020; (c) M. Nishiyama, T. Yamamoto, Koie,

140 Tetrahedron Lett. 1998, 39, 617; (d) J. F. Hartwig, M. Kawatsura, S. I. Hauck, K. H. Shaughnessy, L. M. Alcazar-Roman, J. Org. Chem., 1999 , 64, 5575; (e) A. F. Littke, G. C. Fu, J. Org. Chem., 1999, 64, 10.

${ }^{43}$ For in-line flow FTIR analysis, see: (a) C. F. Carter, I. R. Baxendale, M O'Brien, J. B. J. Pabey and S. V. Ley, Org. Biomol. Chem., 2009, 7, 145 4594; (b) S. Hübner, U. Bentrup, U. Budde, K. Lovis, T. Dietrich, A. Freitag, L. Küpper and K. Jähnisch, Org. Process Res. Dev. 2009, 13, 952; (c) Z. Qian, I. R. Baxendale and S. V. Ley, Chem. Eur. J., 2010, 16, 12342; (d) C. F. Carter, H. Lange, S. V. Ley, I. R. Baxendale, B. Wittkamp, J. G. Goode and N. L. Gaunt, Org. Process Res. Dev., 2010 ,

150 14, 393; (e) P. Koos, U. Gross, A. Polyzos, M. O’Brien, I. Baxendale and S. V. Ley, Org. Biomol. Chem., 2011, 9, 6903; $(f)$ H. Lange, C. F. Carter, M. D. Hopkin, A. Burke, J. G. Goode, I. R. Baxendale and S. V. Ley, Chem. Sci., 2011, 2, 765 .

${ }^{44}$ H. Chiba and K. Tagami, J. Syn. Org. Chem., Jpn. 2011, 69, 124. ${ }_{155}{ }^{45} \mathrm{H}$. Wakami and J. Yoshida, Org. Process Res. Dev., 2005, 9, 787 